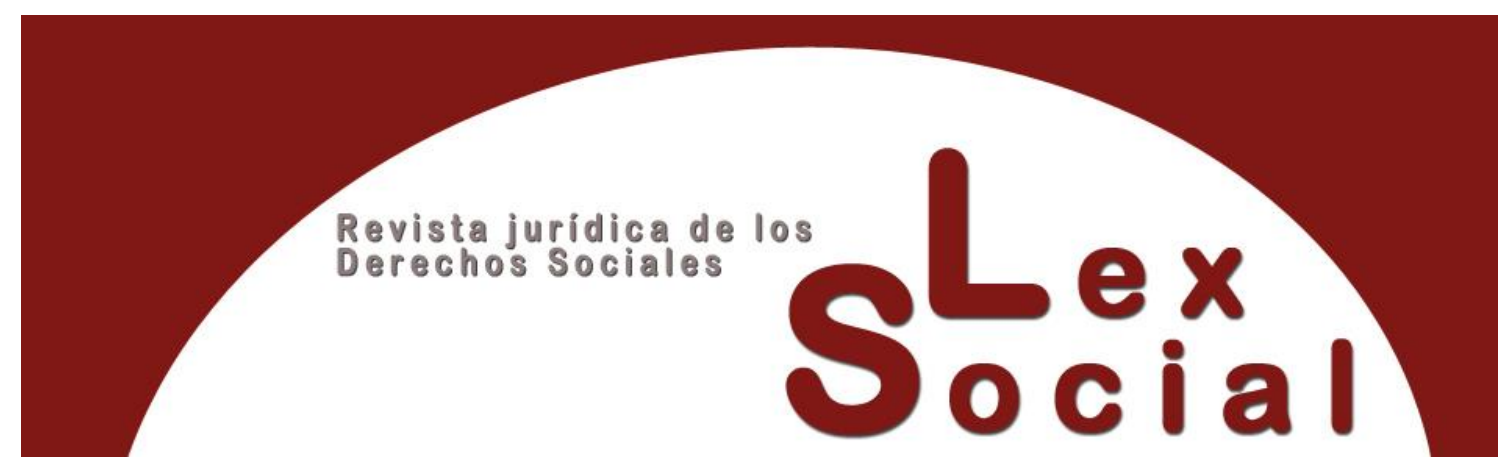

\title{
RECENSIÓN
}

\section{Gallego Losada, Rocío, Las pensiones en la economía digital. Retos y Reformas, Valencia, Tirant lo Blanch, 2021.}

\author{
CARMEN SALCEDO BELTRÁN \\ TU Departamento Derecho del Trabajo y Seguridad Social \\ Universidad de Valencia \\ https://orcid.org/0000-0002-6529-2396
}

Cómo citar este trabajo: Salcedo Beltrán, C. (2022). Gallego Losada, Rocío, Las pensiones en la economía digital. Retos y Reformas, Valencia, Tirant lo Blanch, 2021. Lex Social, Revista De Derechos Sociales, 12 (1), pp. 611-615 https://doi.org/10.46661/lexsocial.6404

La profesora Gallego Losada ha publicado en el año 2021 una obra de indudable interés y actualidad. El sistema de la Seguridad Social en nuestro país lleva ya muchos años pasando por diferentes problemas y retos que numerosos autores han analizado desde diferentes puntos de vista. La originalidad de la obra se encuentra en que se realiza un análisis detallado de los efectos que la nueva economía digital o economía gig está teniendo y va a tener en el sistema de pensiones públicas de jubilación en España.

El libro combina, por tanto, dos elementos que tienen, por separado y de forma individual, un enorme interés, la economía colaborativa de plataformas digitales y su impacto en el mercado laboral, y el sistema de la Seguridad Social en España. Su combinación lleva como resultado a un estudio significativo que pone en relación los problemas que ya venían acusando las pensiones públicas, a los que se suman los nuevos así como la intensificación de los ya existentes que la irrupción de la economía digital provocará.

Este análisis se estructura en cuatro capítulos. El capítulo I aborda la situación del mercado laboral en España en la nueva economía digital. La autora destaca un elemento básico de las empresas en la economía gig, la flexibilidad que estas deben tener en todos los elementos de su funcionamiento y, más concretamente, en las relaciones laborales. La capacidad de poder disponer de productores que se adapten inmediatamente a las

\section{$(\mathrm{cc})$ EY-NC-SA}


demandas de los consumidores constituye una de sus rasgos propios, que le otorga varias ventajas para la economía en su conjunto (uso más eficiente de los recursos) y para los consumidores (ampliación de la oferta de nuevos productos y reducción de su precio), aunque también puede provocar elementos negativos (competencia desleal, desprotección del consumidor final al no contar con garantías de calidad del producto, creación de monopolios y problemas de protección de datos personales). Pero es en el mercado laboral donde los perjuicios asociados a la flexibilidad son más destacados, a pesar de algunas ventajas como la flexibilidad de horario que permite conciliar el trabajo con su vida personal, de estudio o de ocio, las oportunidades de trabajo para ciertos colectivos o la eliminación de discriminaciones por razón de raza, religión o género.

Una de las aportaciones más destacables es el análisis de las desventajas de la flexibilidad del trabajo en la economía gig, donde predominan las relaciones de trabajo "atípicas" frente a la relación "típica", más clásica propia de los trabajadores por cuenta ajena con contrato estable. Este análisis profundiza en la relación entre este, con la contratación indefinida, y el trabajo precario, estableciendo claramente las figuras jurídicas asociadas a esas relaciones, desde el contrato laboral de un trabajador por cuenta ajena, pasando por el trabajo por cuenta propia, el trabajador autónomo económicamente dependiente y el empresario individual.

También se ha de poner en relieve la rigurosa investigación sobre la controversia jurídica de la laboralidad de los trabajadores en empresas gig en los apartados 3 y 4 de este capítulo. Especialmente interesante es el análisis de las notas de dependencia y ajenidad que delimitan la existencia de esa laboralidad. Tras un análisis histórico sobre la aparición del derecho laboral y de estas notas que definen una relación laboral, la autora muestra como la nota de ajenidad, que es casi exclusiva de derecho laboral español, dificulta la constatación de laboralidad de los trabajadores de la economía gig, ya que muchas de sus características (elección de horario, posibilidad de rechazar pedidos, posesión de elementos de trabajo como el teléfono móvil o el vehículo de transporte) son opuestas a la ajenidad. No obstante, los órganos judiciales y, finalmente, el Tribunal Supremo en una sentencia de 2020, han reconocido la laboralidad de estos trabajadores, al demostrar su dependencia y dar más relevancia a la aplicación informática que poseen las empresas y que es clave para el desarrollo del negocio, frente a la ausencia de ajenidad anteriormente indicada.

No obstante, la controversia no ha concluido con este pronunciamiento -que se limita a un sector muy específico, el reparto de comida a domicilio- ni con la aprobación de la denominada Ley Rider cuyo alcance es muy pequeño, tanto por afectar de nuevo solamente al sector de reparto a domicilio, como por introducir simplemente una disposición adicional que introduce la presunción de laboralidad, lo que en palabras de la autora ha "descafeinado" las expectativas que había levantado esta Ley. Las cartas siguen sobre la mesa, y las diferentes posturas, claramente presentadas en el texto, siguen defendiendo desde el mantenimiento de la actual legislación laboral y su aplicación firme en la economía gig, hasta los autores que defienden la creación de una nueva legislación que se adapte a los nuevos trabajos en plataforma. Se defiende esta segunda opción, 
inspirándose en otras legislaciones como el Act $A B 5$ de California, bajo la idea, que yo también comparto, de que la legislación debe "proteger siempre a la parte más débil, para compensar el desequilibrio del poder negociador de las partes, incluyendo a los trabajadores autónomos en situación social y económica muy parecida a los trabajadores por cuenta ajena".

La conexión entre los efectos de la economía gig en el mercado laboral y el sistema de la Seguridad Social se centra en que la economía gig está reduciendo la importancia de los empleos asalariados a tiempo completo, y esta reducción del trabajo estable afecta negativamente a la sostenibilidad de las pensiones públicas. Con esto, se centra el análisis en la Seguridad Social en los capítulos II y III. El lector interesado en la historia de la Seguridad Social, desde sus precedentes en los diferentes sistemas de seguros sociales y mutualidades de la primera mitad del siglo XX, hasta su desarrollo durante el actual periodo democrático que le ha hecho convertirse en uno de los pilares fundamentales del moderno estado del bienestar en España, tiene en este libro una interesante fuente de consulta. Pero más allá de la descripción del sistema público de pensiones, caracterizado por combinar dos sistemas en uno, uno de naturaleza asistencial y otro de naturaleza contributiva, la rigurosa descripción de las características y la evolución de la Seguridad permite atisbar los graves problemas a los que se enfrenta. Concretamente, la situación de déficit de la Seguridad Social causada por la reducción de las cotizaciones sociales y el aumento del gasto en pensiones, cuyas causas últimas están en el envejecimiento demográfico que ha tensionado el modelo español de reparto de corte bismarckianomediterráneo articulado a través de las cotizaciones sociales.

Una debilidad intrínseca del sistema de pensiones públicas que se refleja en el difícil equilibrio existente entre los tres pilares del sistema, la equidad intergeneracional, la solidaridad y la contributividad. A partir de esta debilidad, el libro analiza las sucesivas reformas que han tratado de corregir estos problemas. La más destacada es la reforma del año 2013, con sus dos medidas estrella de contención del gasto, el Factor de Sostenibilidad y el Índice de Revalorización de las Pensiones, influenciada por la grave crisis económica y financiera de 2008, y cuya fallida puesta en marcha, hasta su derogación definitiva en fechas muy recientes, es una muestra de las dificultades políticas para establecer reformas adecuadas para la supervivencia del sistema de pensiones en España. La exhaustiva explicación que hace la autora de esta reforma y de su infructuosa aplicación muestra de forma clara la inevitabilidad de la decadencia de todo este sistema.

El capítulo III continúa con la misma línea anterior, mostrando de nuevo la reacción política respecto a la Seguridad Social tras una nueva crisis económica, esta vez derivada de la pandemia. La impresión tras la lectura de estas líneas es que de nuevo se repiten las mismas circunstancias, reacciones y errores que ya se cometieron en el pasado. El examen de otros elementos de la Seguridad Social, como el Fondo de Reserva o los Pactos de Toledo, ahondan en esta deprimente descripción. El capítulo termina con la nueva reforma del sistema de la Seguridad Social que ha comenzado a desarrollarse tímidamente en 2021 y que está previsto que introduzca sus principales medidas en 2022. Vuelve a aparecer una impresión de déjà vu, de repetirse las mismas circunstancias una y otra vez, 
admitiendo el gobierno la necesidad de introducir reformas que al final reducen las pensiones, con la sustitución del Factor de Sostenibilidad de las Pensiones por un mecanismo de equidad intergeneracional que no deja de ser lo mismo pero cambiándole el nombre; continuando con la disminución del elemento contributivo de las pensiones para dar más peso a su faceta asistencial; reduciendo las pensiones mediante reformas paramétricas como el retraso de la edad de jubilación o el aumento de los años cotizados; y estableciendo trucos contables para pasar los déficit y las deudas del sistema de la Seguridad Social de un organismo a otro, algo que no tiene ninguna utilidad práctica salvo tratar de disimular los datos cada vez más preocupantes de este sistema. En definitiva, la autora nos muestra una evolución que no parece atisbar en el horizonte cercano ninguna solución a los restos a largo plazo de este sistema.

También se explican las posibles opciones que se podrían establecer, o que no habrá más remedio que realizar, para tratar de revertir esta situación. La profundización de las reformas paramétricas, concretamente incrementando las cotizaciones sociales, es una primera opción de muy probable aplicación, aunque tendrá efectos negativos en la creación de empleo. Asimismo, se plantea renovar y revisar los criterios que rigen las pensiones de viudedad, sobre todo tras los cambios en el papel de la mujer en el mercado laboral. Otra opción que está sobre la mesa es que parte del coste de las pensiones se costeen mediante los Presupuestos Generales del Estado, lo cual debilitaría aún más el principio de contributividad en el que se basa el sistema actual.

Esta búsqueda de posibles soluciones para los retos del sistema público de pensiones continúa en el capítulo IV, relacionándolo con la nueva realidad económica y social derivada de los efectos de la nueva economía digital, ya explicada anteriormente en el primer capítulo. El nuevo paradigma digital no es más que otro elemento que pone en tensión el sistema público de pensiones, igual que lo fueron la crisis financiera de 2008 y la crisis de la Covid-19. En este caso, la nueva economía de plataformas y la robotización de la producción provoca una reducción en el número de nuevos trabajadores y de su capacidad de cotización, lo que pone en peligro las pensiones de los actuales cotizantes. Surge así el problema de los colectivos precarizados y su encaje en el sistema de pensiones. Esto enlaza con otros problemas que se pueden presentar en el futuro, como la posible ruptura de la caja única de las pensiones por la presión de algunas comunidades autónomas, la continuación del uso y abuso de las jubilaciones anticipadas, o la ruptura del pacto social en un cambio silencioso del modelo donde la solidaridad se imponga a la contributividad. Elementos concretos de las principios anteriores son la eliminación de los topes máximos de las cotizaciones máximas, sin el consiguiente incremento de las pensiones máximas, la progresiva importancia del presupuesto público en las pensiones, lo que reduce su carácter contributivo, el aumento de las cotizaciones de los trabajadores autónomos, un impuesto finalista al estilo de la Contribución Social Generalizada francesa, o un muy interesante y extenso examen de la posibilidad de establecer un impuesto a los robots.

El capítulo concluye con la consideración de otras opciones planteadas para mejorar la financiación de las pensiones. El gobierno actual pretende promocionar el segundo pilar 
de las pensiones en España, el del ahorro privado a través de las empresas, con un fondo de pensiones colectivo de promoción pública. Esta es la única alternativa que se ha puesto sobre la mesa, pues el resto no tienen hoy en día visos de desarrollarse. Se refiere al tercer pilar con los planes de pensiones individuales, que el gobierno está reduciendo, y otras opciones que llevan mucho tiempo planteándose, pero que no parece que tengan mucho apoyo político o social, como el reforzamiento del sistema de reparto a través de las Cuentas Nocionales o la Hipoteca Inversa. En definitiva, la siempre complicada reforma del sistema de pensiones públicas en España y su adaptación a la nueva economía digital se puede valorar con este trascendental estudio. 